\title{
Commitment issues
}

\author{
Around the world, in developed and developing countries, there is reluctance to commit to the \\ alleviation of climate change. But investment in clean energy is growing.
}

Throughout December 2009, the big story was the United Nations Framework Convention on Climate Change (UNFCCC) and its two-week meeting held in Copenhagen, Denmark. Presidents and popstars descended, yet the summit failed to reach the kind of binding international agreement on emissions and other climate issues that was noisily demanded by campaigners, and indeed by many national governments. The 'Copenhagen accord' stated the aim of keeping the global average temperature increase at no more than 2 degrees - but contained no commitment to the measures that might achieve it.

One year on, the UN climate summit reconvened, this time in Cancún, Mexico, and is entering its final stages as Nature Physics goes to press. This year's summit had none of the fanfare of its predecessor - which might inspire the hope that its delegates are instead able to work quietly but determinedly towards a more meaningful conclusion. That hope might be coming, if only in small part, to some kind of fruition.

In 2009, China was cast as the villain of the Copenhagen pantomime, held responsible for the removal from the accord, in closed sessions, of clauses setting targets of a 1.5-degree rise in global temperature this century and an $80 \%$ cut in global $\mathrm{CO}_{2}$ emissions by 2050. Reports from Cancún suggest, however, that China is now showing a greater willingness to negotiate and institute curbs on its emissions, and in particular to discuss the issue of the verification of cuts - a major sticking point with the US government. Although coal is still vital to the burgeoning Chinese economy, the country is cutting down on carbon and has become the world's biggest producer of renewable energy sources based on wind and solar power.

Even though a similar US-China face-off may have been avoided this year, the political will to tackle climate change is still crushingly insufficient. Not one leader of a G20 nation is attending the Cancún summit. In her address to the conference, the executive secretary of the UNFCCC Christiana Figueres stressed that "the stakes at this particular conference are very high. The political stakes are high because the effectiveness and credibility of your multilateral intergovernmental process are in danger. And the environmental stakes are high because we are quickly running out of time to safeguard our future."

She went on to cite this year's floods in Pakistan, Venezuela and Colombia, wildfires in Russia, record hot summers in Japan and China and the plight of island nations such as the Maldives that are having to consider evacuation procedures in the face of rising sea-levels. And yet already even the possibility of managing a 2-degree cap on rising temperature may be slipping away: a special issue of Philosophical Transactions of the Royal Society A, published to coincide with the summit, documents the potential for and implications of a 4-degree rise; that rise could occur as soon as 2060 according to the worst-case scenario, and would push the population in many areas of the world beyond their capacity to adapt.

Adaptation is a key strategy in dealing with climate change - including how the developed world adapts its own lifestyle and resource consumption. Economic interests are clearly hampering progress, and now the UK's Climate Change Committee, in their latest report, has called for a revolution in the country's power industry. The free market is not investing in or delivering the clean energy that the country (or indeed the world) needs. The committee suggests instead that the government should decide the amount of clean energy needed and then ask private companies to bid to provide it.

Also pushing the clean-energy agenda ahead of the Cancún summit was US energy secretary, and physicist, Steven Chu. Chu is urging much greater US investment in the research and development of clean-energy technology, on top of the $\$ 80$ billion directed there from last year's financial-stimulus package. In the face of the substantial progress made by China, and also by India, he called this a "Sputnik moment", at which the US had the choice to push to be an innovative leader of the technology, or to fall behind, as it once had a choice to meet the Soviet challenge in the space race. The world, he said, "essentially needs a new industrial revolution. But time is running out."

Meanwhile, Europe is having a Sputnik moment of its own, forging ahead with an ambitious scheme to build an under-sea grid for the distribution of wind power. On 3 December 2010, ten countries - Norway,

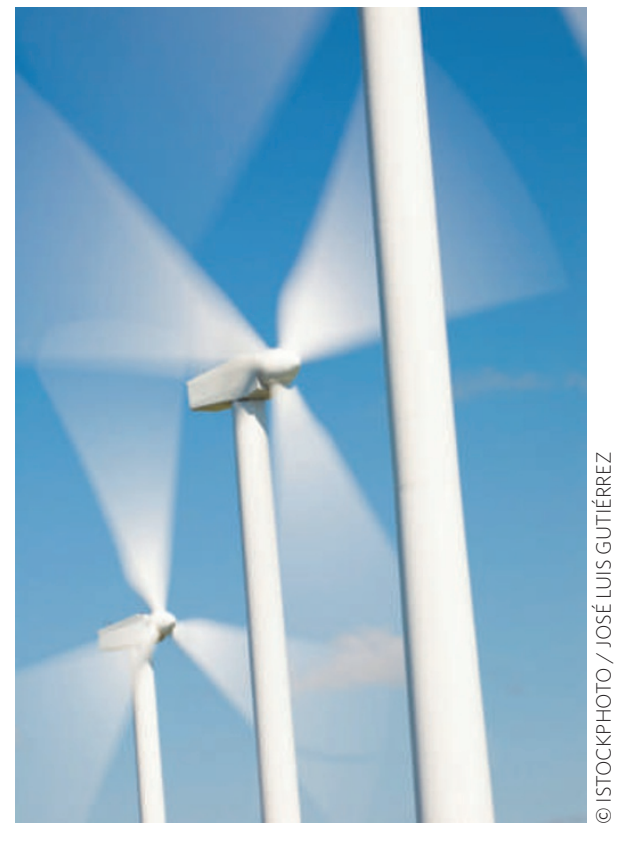

Sweden, Denmark, France, Germany, the United Kingdom, Ireland, the Netherlands, Belgium and Luxembourg - signed a memorandum of understanding for the $€ 20$-billion project. Clusters of wind turbines, scattered mostly across the North Sea, will generate the clean power that will enable the meeting of emissions targets set within the European Union. (There are also proposals for similar grids to pump wind and solar power from the Sahara to Europe, and wind power from the North Atlantic to the eastern United States.) But first there are some major issues of electrical engineering to overcome - not least a need for the tools to handle electricity as d.c. rather than a.c. (the a.c. losses are too great in buried cables over such distances).

Some commitment to the alleviation of climate change is, then, in evidence. China, the United States, Europe and others are moving on the issue, although that movement is as yet still slow and lumbering. Furthermore, the much-maligned Kyoto Protocol on climate change expires in 2012. Putting even the most positive spin on the progress of the Cancún summit, it is difficult to feel much confidence in the world's ability to agree a new protocol and commit, properly, to tackling the threat of climate change. 